\title{
Lebanese students' motivation in medical school: does it change throughout the years? A cross-sectional study
}

Anne-Sophie Sarkis ${ }^{1 *}$, Souheil Hallit ${ }^{2,3}$, Aline Hajj ${ }^{4,5}$, Anthony Kechichian ${ }^{1}$, Dolla Karam Sarkis ${ }^{4,6}$, Antoine Sarkis ${ }^{1,7}$ and Eliane Nasser Ayoub ${ }^{1,8}$

\begin{abstract}
Background: Students entering medical school are driven by different types of motivation: autonomous motivation, controlled motivation, or amotivation. Motivation types can influence students' performance, outcome and well-being. To our knowledge, this topic has never been studied in Lebanese medical students. This study aims to identify students' motivation types in the first 5 years of medical school at two Lebanese universities (USJ and USEK). It also aims to determine the predominant motivation type of the whole sample. Results may be the first step towards raising awareness about this topic and implementing actions that enhance autonomous motivation.

Methods: A cross-sectional study was performed between January and June 2017. A questionnaire was sent to medical students by e-mail. The students' academic motivation was assessed using the Academic Motivation Scale.

Results: A higher mean autonomous motivation score was found in each academic year, as compared to the mean controlled motivation and amotivation scores. The highest mean autonomous motivation score was seen among second year students, whereas the lowest score was noted in fifth year students. The highest scores for controlled motivation and amotivation belonged to the fourth-year students, and the lowest to the first-year students. Students who were still satisfied with medical studies had a higher autonomous motivation score. Finally, USJ students who were satisfied with their second year training had a higher mean autonomous motivation score than those who were not.

Conclusion: This study showed high levels of autonomous motivation in the first five years of medical school. Autonomous motivation was the predominant type in the whole sample. The highest scores of controlled motivation and amotivation were noted in the fourth year. Moreover, high levels of self-determination were seen in students who enjoyed their early contacts with patients through trainings. Actions should be implemented in medical schools to enhance and maintain autonomous motivation, and consequently students' outcome and health-care quality.
\end{abstract}

Keywords: Amotivation, Extrinsic motivation, Instrinsic motivation, Medicine, Students

\footnotetext{
* Correspondence: annesophiesarkis@gmail.com

${ }^{1}$ Faculty of Medicine, Saint-Joseph University, Beirut, Lebanon

Full list of author information is available at the end of the article
}

(c) The Author(s). 2020 Open Access This article is licensed under a Creative Commons Attribution 4.0 International License, which permits use, sharing, adaptation, distribution and reproduction in any medium or format, as long as you give appropriate credit to the original author(s) and the source, provide a link to the Creative Commons licence, and indicate if changes were made. The images or other third party material in this article are included in the article's Creative Commons licence, unless indicated otherwise in a credit line to the material. If material is not included in the article's Creative Commons licence and your intended use is not permitted by statutory regulation or exceeds the permitted use, you will need to obtain permission directly from the copyright holder. To view a copy of this licence, visit http://creativecommons.org/licenses/by/4.0/ The Creative Commons Public Domain Dedication waiver (http://creativecommons.org/publicdomain/zero/1.0/) applies to the data made available in this article, unless otherwise stated in a credit line to the data. 


\section{Background}

The concept of motivation has become an important research subject in the field of education. "Motivation" can be defined as "a reason for acting or behaving in a particular way" [1]. A widely-used approach to motivation is the theory of Deci and Ryan [2]. This theory was elaborated in the 1980s, and is based on the level of selfdetermination. It states that motivation can be internally or externally generated, with a higher or lower level of self-determination, respectively. A motivation type can be identified for each student (Fig. 1). A student with genuine interest in medicine has an intrinsic motivation. Someone studying medicine because of external factors has an extrinsic motivation, which can be further subclassified: external motivation with identified regulation (e.g., studying medicine to reach a personal goal, with little interest in medicine itself), introjected regulation (e.g., behavior influenced by social expectations or by internalized controllers), and external regulation (e.g., behavior influenced by the system of punishment and reward). Finally, if students have no interest at all in medicine, they are classified as amotivated. Intrinsic motivation and extrinsic motivation with identified regulation are considered "autonomous motivation", whereas extrinsic motivation with introjected and external regulations are considered "controlled motivation" [3].

Types of motivation are key elements in any educational system as they shape students' behavior, along with their consequent performance and outcome [4]. According to the self-determination theory, intrinsic motivation and autonomous forms of self-regulation are desirable since they have been associated with deep learning, better performance and well-being [5]. Three basic psychological needs have to be satisfied in order to achieve intrinsic motivation: the needs for autonomy, competence and relatedness. Autonomy refers to making decisions by one's own will, based on their needs and values. Competence refers to the desire of feeling capable of performing a determined task. As for relatedness, it is the need for belongingness or connectedness with a significant community [4, 6-9]. Thus, several pedagogic strategies that stimulate internalization of motivation and autonomous types of motivation have been recently evaluated [10].

Previous studies have associated motivation types to different factors, including gender, academic year, and learning methods. Actually, studies have shown that intrinsic motivation is more prone to decline with the years of medical school [11]. Sobral's [12] and Kusurkar's [13] studies revealed that girls are more intrinsically motivated than boys. Finally, students who enjoy their clinical trainings have higher levels of self-determination [14].

To the best of our knowledge, no previous studies regarding motivation types in medical students have been previously conducted in Lebanon. The current study attempts to test and compare the case of medical students in Lebanon to results of studies conducted in other countries and, thus, bringing awareness to the Lebanese medical field on the topic of students' motivation. Therefore, we decided to study the motivation types of students at the Faculty of Medicine of two different Lebanese universities: Saint-Joseph University of Beirut (USJ), and the Holy Spirit University of Kaslik (USEK). These two faculties follow the European Credit Transfer System (ECTS). The Faculty of Medicine of USJ has a larger number of students and more trainings during the curriculum, compared to that of USEK. At USJ, students have a nursing training in second year, a physical examination training in

\begin{tabular}{|c|c|c|c|c|c|c|}
\hline & \multicolumn{5}{|c|}{ Non self-determined } & \multirow{2}{*}{$\begin{array}{l}\text { Self-determined } \\
\text { Intrinsic } \\
\text { Motivation }\end{array}$} \\
\hline & Amotivation & \multicolumn{4}{|c|}{ Extrinsic Motivation } & \\
\hline Regulatory style: & $\begin{array}{l}\text { Non- } \\
\text { Regulation }\end{array}$ & $\begin{array}{c}\text { External } \\
\text { Regulation }\end{array}$ & $\begin{array}{l}\text { Introjected } \\
\text { Regulation }\end{array}$ & $\begin{array}{l}\text { Identified } \\
\text { Regulation }\end{array}$ & $\begin{array}{l}\text { Integrated } \\
\text { Regulation }\end{array}$ & $\begin{array}{l}\text { Intrinsic } \\
\text { Regulation }\end{array}$ \\
\hline Source of motivation: & Impersonal & External & $\begin{array}{c}\text { Somewhat } \\
\text { external }\end{array}$ & $\begin{array}{c}\text { Somewhat } \\
\text { internal }\end{array}$ & Internal & Internal \\
\hline Motivation regulators: & $\begin{array}{c}\text { No intention } \\
\text { Incompetence } \\
\text { Lack of } \\
\text { control }\end{array}$ & $\begin{array}{l}\text { Compliance } \\
\text { External } \\
\text { rewards or } \\
\text { punishments }\end{array}$ & $\begin{array}{l}\text { Ego- } \\
\text { involvement } \\
\text { Approval } \\
\text { from others }\end{array}$ & $\begin{array}{l}\text { Valuing an } \\
\text { activity } \\
\text { Endorsement } \\
\text { of goals }\end{array}$ & $\begin{array}{l}\text { Congruence } \\
\text { Synthesis } \\
\text { with self }\end{array}$ & $\begin{array}{l}\text { Interest } \\
\text { Enjoyment } \\
\text { Inherent } \\
\text { satisfaction }\end{array}$ \\
\hline
\end{tabular}

The Self-Determination Continuum

Fig. 1 The Self-Determination Continuum (https://learningsnippets.files.wordpress.com/2013/10/sdt-continuum.png) 
third year, and observerships in fourth and fifth years. At USEK, they have a nursing training in third year, and observerships in fourth and fifth years.

The primary objective of this reported study was to identify the types of students' motivation across the first 5 years of the medical program at USJ and USEK, and determine the predominant type in the whole sample. The secondary objective was to identify variables that affect these motivation types. We hypothesized that autonomous motivation should increase with the years of the curriculum, since students get closer to practice, and that it should be the predominant type in the whole sample.

We hope this study helps create awareness for motivation types in the Lebanese medical system. It may reveal the variables that could be modified in order to enhance self-determination. It can benefit teachers, who could implement actions to support students' autonomous motivation [5]. Additionally, it can benefit students, who will be aware of their motives and types, and enhance health care delivery.

\section{Methods}

Study design

A cross-sectional study was conducted to focus on types of motivation among medical students in Lebanon.

\section{Setting}

The study was performed between January and June 2017, in the faculties of medicine at USJ and USEK. A list of enrolled students was provided by the administration of both faculties. USJ students were first approached in January 2017. USEK students participated in the study later, in June 2017.

\section{Participants}

All 581 students from the first 5 years of the medical program were targeted (431 from USJ, 150 from USEK).

\section{Questionnaire}

The questionnaire used in this study was adapted from the Academic Motivation Scale (AMS). We adapted each item of the questionnaire to the context of the medical field. The questionnaire was accessed online using two links, one for USJ and one for USEK. Those links were sent via emails to all medical students at participating universities. Reminders to answer were sent every 2 weeks for 6 weeks. There were no exclusion criteria. Each student was allowed to fill the questionnaire once.

In the first part of the survey, students were asked to enter their socio-demographic details (age, gender, marital status, year of study), and respond to a questionnaire on whether they belonged to a medical family or not, whether they lived with their parents or not, the reason for choosing a medical program, and the degree of satisfaction with their choice. The second part of the survey aimed at assessing the students' type of motivation. The latter was studied using the Academic Motivation Scale in Education-University Studies (AMS), developed and validated in Quebec $[11,15]$. This instrument was developed based on the theory of self-determination of Deci and Ryan $[4,11,12]$. It adds three subscales to intrinsic motivation, thus encompassing seven types of motivation: intrinsic motivation to knowledge (MICO), intrinsic motivation for accomplishment (MIAC), intrinsic motivation to stimulation (MIST), extrinsic motivation by identified regulation (MEID), extrinsic motivation by introjected regulation (MEIN), external extrinsic motivation (ERM), amotivation (AMOT). The questionnaire includes 28 items, grouped into those seven types. For each of the 28 items, the student had to specify to which extent the proposed statement is a reason for continuing medical studies on a five-point Likert scale, ranging from "strongly disagree" to "strongly agree". Questions related to trainings of students during the first 5 years were also incorporated in the questionnaire. Students were asked about their satisfaction with the different trainings, and whether they wished to have more training hours.

\section{Statistical analysis}

The collected data were analyzed using Statistical Package for Social Sciences (SPSS) software, version 23. The frequency of the quantitative variables was reported as the mean \pm standard deviation, while the frequency of the qualitative variables was expressed in frequency and percentages. The Chi-2 test was used for dichotomous or multinomial qualitative variables. To confirm the validity of the questionnaire of students' motivation types in the Lebanese population, a factor analysis was launched respectively for the questions of each type, using the principal component analysis technique with a Promax rotation since the extracted factors were found to be significantly correlated. The measurement of Kaiser-Meyer-Olkin sampling ability and the Bartlett sphericity test were found to be adequate. The number of factors retained corresponded to Eigen values greater than one. In addition, reliability of the scale's items was assessed by Cronbach's alpha values. A $p<0.05$ was considered significant.

\section{Results}

Out of 581 questioned students, 206 (35.5\%) filled the questionnaire. The sociodemographic and other characteristics of the participants are summarized in Table 1.

\section{Factor analysis}

Among all the questions asked in the questionnaire, all variables, except question 7, could be extracted from the list during the factor analysis, since none of the questions were strongly correlated with another question $(r>0.9)$, had a low load factor $(<0.3)$ or a low community level $(<0.3)$. It 
Table 1 Sociodemographic and other characteristics of the sample $(N=206)$

\begin{tabular}{|c|c|c|c|}
\hline & USJ $(\boldsymbol{N}=145)$ & USEK $(\boldsymbol{N}=61)$ & $p$-value \\
\hline Year of study & & & 0.035 \\
\hline 1st year & $50(34.5 \%)$ & $13(21.3 \%)$ & \\
\hline 2nd year & $15(10.3 \%)$ & $11(18 \%)$ & \\
\hline 3rd year & $21(14.5 \%)$ & $13(21.3 \%)$ & \\
\hline 4th year & $13(9 \%)$ & $11(18 \%)$ & \\
\hline 5th year & $46(31.7 \%)$ & $13(21.3 \%)$ & \\
\hline Repeating the academic year & & & 0.526 \\
\hline No & $144(99.3 \%)$ & 60 (98.4\%) & \\
\hline Yes & $1(0.7 \%)$ & $1(1.6 \%)$ & \\
\hline Gender & & & 0.635 \\
\hline Male & $59(40.7 \%)$ & $27(44.3 \%)$ & \\
\hline Female & $86(59.3 \%)$ & $34(55.7 \%)$ & \\
\hline \multicolumn{4}{|l|}{ Marital status } \\
\hline Single & $144(100 \%)$ & $61(100 \%)$ & - \\
\hline Belonging to a medical family & & & 0.742 \\
\hline No & $108(74.5 \%)$ & $46(76.7 \%)$ & \\
\hline Yes & 37 (25.5\%) & $14(23.3 \%)$ & \\
\hline Living with parents & & & 0.043 \\
\hline No & $18(12.4 \%)$ & $2(3.3 \%)$ & \\
\hline Yes & $127(87.6 \%)$ & $59(96.7 \%)$ & \\
\hline \multicolumn{4}{|l|}{ Reason to be a doctor } \\
\hline Vocation and passion for medicine & $115(79.3 \%)$ & $52(85.2 \%)$ & 0.321 \\
\hline Familial pressure & $7(4.8 \%)$ & $4(6.6 \%)$ & 0.614 \\
\hline It's a business that earns money & $37(25.5 \%)$ & $15(24.6 \%)$ & $<0.001$ \\
\hline For the benefits that this profession brings, especially in Lebanon & $45(31 \%)$ & $11(18 \%)$ & 0.056 \\
\hline It's a liberal job & $77(53.1 \%)$ & $11(18 \%)$ & $<0.001$ \\
\hline For the humanitarian side of the profession & $105(72.4 \%)$ & $37(60.7 \%)$ & 0.096 \\
\hline \multicolumn{4}{|l|}{ Satisfaction with choice of medical studies } \\
\hline Yes & $121(84 \%)$ & $54(88.5 \%)$ & 0.405 \\
\hline \multicolumn{4}{|l|}{ Choice of specialty fixed from the beginning } \\
\hline Yes & $42(29 \%)$ & $21(34.4 \%)$ & 0.437 \\
\hline \multicolumn{4}{|l|}{ Choice of specialty modified during your medical studies } \\
\hline Yes & $85(60.3 \%)$ & 39 (63.9\%) & 0.625 \\
\hline Choice of specialty & & & 0.594 \\
\hline Medical specialty & $63(43.4 \%)$ & $22(36.1 \%)$ & \\
\hline Surgery & $42(29 \%)$ & 21 (34.4\%) & \\
\hline Others & $40(27.6 \%)$ & $18(29.5 \%)$ & \\
\hline
\end{tabular}

is of note that question 7 was removed from the analysis due to a low communality $<0.3$.

The factor analysis for the motivation type questionnaire for medical students was carried out on the entire sample $(n=$ 206). The questionnaire elements converged on a solution of three factors, explaining a total of $81.51 \%$ of the variance (factor 1: items related to autonomous motivation; factor 2: items related to controlled motivation; factor 3: items related to amotivation). A Kaiser-Meyer-Olkin measurement of sampling adequacy of 0.975 was found, with a significant Bartlett's test of sphericity $(p<0.001)$. In addition, a high Cronbach alpha was found for the whole scale (0.984) (Table 2). 
Table 2 Factor analysis of the Academic Motivation Scale at the faculties of medicine of USJ and USEK

\begin{tabular}{|c|c|c|}
\hline Factor 1 & Item number & $\begin{array}{l}\text { Loading on } \\
\text { factor }\end{array}$ \\
\hline \multicolumn{3}{|l|}{ Why do you go to medical school? } \\
\hline For the pleasure that I experience when I discover the theories of famous researchers. & 11 & 1.044 \\
\hline For the pleasure that I experience when I feel completely absorbed by medical studies and sciences. & 18 & 1.035 \\
\hline For the pleasure I experience while surpassing myself in my medical studies. & 6 & .942 \\
\hline For the pleasure that I experience in broadening my knowledge about subjects which appeal to me. & 16 & .911 \\
\hline For the pleasure I experience when I discover new things in medicine that I have never seen before. & 9 & .908 \\
\hline For the pleasure that I experience while I am surpassing myself in one of my personal accomplishments. & 13 & .881 \\
\hline Because I experience pleasure and satisfaction while learning new things related to the medical field. & 2 & .872 \\
\hline For the "high" feeling that I experience while learning about breakthroughs in the medical field. & 25 & .858 \\
\hline Because my medical studies allow me to continue to learn about many things that interest me. & 23 & .858 \\
\hline For the intense feelings I experience when I am communicating my own ideas to others about a medical subject. & 4 & .783 \\
\hline Because I think that a college education will help me better prepare for the career I have chosen. & 3 & .766 \\
\hline For the satisfaction I feel when I am in the process of accomplishing difficult academic activities. & 20 & .749 \\
\hline Because medical school allows me to experience a personal satisfaction in my quest for excellence in my studies. & 27 & .683 \\
\hline Because eventually it will enable me to enter the job market in a field that I like. & 10 & .664 \\
\hline Because this will help me make a better choice regarding my career orientation. & 17 & .529 \\
\hline Because I believe that a few additional years of medical education will improve my competence as a worker. & 24 & .489 \\
\hline \multicolumn{3}{|l|}{ Factor 2} \\
\hline In order to have a better salary later on. & 22 & .932 \\
\hline Because I want to have "the good life" later on. & 15 & .903 \\
\hline In order to obtain a more prestigious job later on. & 8 & .862 \\
\hline Because with only a high-school degree I would not find a high-paying job later on. & 1 & .724 \\
\hline To show myself that I am an intelligent person. & 21 & .683 \\
\hline Because I want to show myself that I can succeed in my medical studies. & 28 & .680 \\
\hline Because of the fact that when I succeed in medical school I feel important. & 14 & .546 \\
\hline \multicolumn{3}{|l|}{ Factor 3} \\
\hline $\begin{array}{l}\text { I don't know; I can't understand what I am } \\
\text { doing in medical school. }\end{array}$ & 26 & .960 \\
\hline Honestly, I don't know; I really feel that I am wasting my time in medical school. & 5 & .913 \\
\hline I can't see why I go to medical school and frankly, I couldn't care less. & 19 & .839 \\
\hline I once had good reasons for going to medical school; however, now I wonder whether I should continue. & 12 & .792 \\
\hline
\end{tabular}

\section{Bivariate analysis}

The total scores of autonomous motivation, controlled motivation and amotivation were computed based on the factor analysis results by adding the answers of the questions that constitute each factor. The average score was calculated by dividing the total score by the number of questions forming each factor. The results showed that the mean autonomous motivation score was $3.04 \pm$ 0.94, whereas controlled motivation and amotivation scores were respectively $2.55 \pm 1.02$ and $1.64 \pm 079$.

In order to evaluate the variables that affect types of motivation, bivariate analyses have been performed. Results are summarized in Table 3. In the studied sample, a higher mean autonomous motivation score was found in each academic year, in comparison to mean controlled motivation and amotivation scores. The highest score for autonomous motivation $(3.42 \pm 0.92, p<0.001)$ belongs to the second-year students, and the lowest score for the same $(2.74 \pm 0.80)$ to the fifth-year students. The highest scores for controlled motivation $(3.06 \pm 1.20, p<0.001)$ and amotivation $(2.12 \pm 0.96, p<0.001)$ belong to the fourth-year students. However, the lowest score of controlled motivation and amotivation (respectively $2.30 \pm$ 0.92 and $1.38 \pm 0.61$ ) belongs to the first-year students.

As for score comparison within other variables, a higher mean autonomous motivation score was found in students who lived with their parents $(3.09 \pm 0.96, p=$ 0.018 ), who chose to be a doctor because it was their 
Table 3 Bivariate analysis of the different scores with the sociodemographic variables among the whole sample

\begin{tabular}{|c|c|c|c|}
\hline Variable / scores & Autonomous Motivation & Controlled Motivation & Amotivation \\
\hline \multicolumn{4}{|l|}{ Gender } \\
\hline Male & $3.04 \pm 0.92$ & $2.65 \pm 1.00$ & $1.77 \pm 0.93$ \\
\hline Female & $3.04 \pm 0.96$ & $2.47 \pm 1.03$ & $1.55 \pm 0.66$ \\
\hline$p$-value & 0.995 & 0.247 & 0.076 \\
\hline \multicolumn{4}{|l|}{ Year of study } \\
\hline 1st year & $2.88 \pm 0.86$ & $2.30 \pm 0.92$ & $1.38 \pm 0.61$ \\
\hline 2nd year & $3.42 \pm 0.92$ & $2.81 \pm 1.21$ & $1.89 \pm 0.73$ \\
\hline $3 r d$ year & $3.32 \pm 1.02$ & $2.71 \pm 1.14$ & $1.58 \pm 0.68$ \\
\hline 4th year & $3.41 \pm 1.09$ & $3.06 \pm 1.20$ & $2.12 \pm 0.96$ \\
\hline 5th year & $2.74 \pm 0.80$ & $2.38 \pm 0.75$ & $1.65 \pm 0.86$ \\
\hline$p$-value & $<0.001$ & $<0.001$ & $<0.001$ \\
\hline \multicolumn{4}{|c|}{ Doctor in the family } \\
\hline No & $3.05 \pm 0.92$ & $2.54 \pm 0.99$ & $1.70 \pm 0.83$ \\
\hline Yes & $2.97 \pm 0.99$ & $2.53 \pm 1.09$ & $1.45 \pm 0.63$ \\
\hline$p$-value & 0.610 & 0.964 & 0.036 \\
\hline \multicolumn{4}{|c|}{ Living with parents } \\
\hline No & $2.62 \pm 0.70$ & $2.15 \pm 0.62$ & $1.45 \pm 0.61$ \\
\hline Yes & $3.09 \pm 0.96$ & $2.59 \pm 1.04$ & $1.66 \pm 0.81$ \\
\hline$p$-value & 0.018 & 0.016 & 0.311 \\
\hline \multicolumn{4}{|c|}{ Choice of being a doctor by vocation } \\
\hline No & $2.70 \pm 0.99$ & $2.49 \pm 1.01$ & $1.86 \pm 0.85$ \\
\hline Yes & $3.12 \pm 0.92$ & $2.56 \pm 1.02$ & $1.59 \pm 0.77$ \\
\hline$p$-value & 0.017 & 0.696 & 0.072 \\
\hline \multicolumn{4}{|c|}{ Familial pressure } \\
\hline No & $3.04 \pm 0.93$ & $2.53 \pm 1.02$ & $1.63 \pm 0.80$ \\
\hline Yes & $3.03 \pm 1.21$ & $2.86 \pm 1.08$ & $1.82 \pm 0.65$ \\
\hline$p$-value & 0.983 & 0.327 & 0.450 \\
\hline \multicolumn{4}{|c|}{ Business that earns money } \\
\hline No & $3.02 \pm 0.92$ & $2.42 \pm 0.97$ & $1.59 \pm 0.77$ \\
\hline Yes & $3.10 \pm 1.01$ & $2.93 \pm 1.06$ & $1.78 \pm 0.83$ \\
\hline$p$-value & 0.653 & 0.003 & 0.164 \\
\hline \multicolumn{4}{|c|}{ Benefits the profession brings } \\
\hline No & $3.11 \pm 0.94$ & $2.50 \pm 1.03$ & $1.65 \pm 0.82$ \\
\hline Yes & $2.83 \pm 0.93$ & $2.69 \pm 0.98$ & $1.62 \pm 0.70$ \\
\hline$p$-value & 0.075 & 0.269 & 0.831 \\
\hline \multicolumn{4}{|l|}{ Liberal job } \\
\hline No & $3.26 \pm 0.99$ & $2.64 \pm 1.10$ & $1.75 \pm 0.81$ \\
\hline Yes & $2.75 \pm 0.77$ & $2.42 \pm 0.88$ & $1.48 \pm 0.74$ \\
\hline$p$-value & $<0.001$ & 0.139 & 0.026 \\
\hline \multicolumn{4}{|c|}{ Humanitarian side } \\
\hline No & $3.14 \pm 1.01$ & $2.69 \pm 1.07$ & $1.62 \pm 0.76$ \\
\hline Yes & $3.00 \pm 0.91$ & $2.48 \pm 0.99$ & $1.65 \pm 0.81$ \\
\hline$p$-value & 0.367 & 0.209 & 0.794 \\
\hline
\end{tabular}

Still satisfied from your choice 
Table 3 Bivariate analysis of the different scores with the sociodemographic variables among the whole sample (Continued)

\begin{tabular}{|c|c|c|c|}
\hline Variable / scores & Autonomous Motivation & Controlled Motivation & Amotivation \\
\hline No & $2.55 \pm 0.91$ & $2.45 \pm 0.79$ & $2.08 \pm 0.99$ \\
\hline Yes & $3.13 \pm 0.92$ & $2.57 \pm 1.06$ & $1.56 \pm 0.73$ \\
\hline$p$-value & 0.004 & 0.584 & 0.002 \\
\hline \multicolumn{4}{|c|}{ Choice of specialty fixed from the beginning } \\
\hline No & $2.96 \pm 0.89$ & $2.50 \pm 0.99$ & $1.60 \pm 0.78$ \\
\hline Yes & $3.24 \pm 1.03$ & $2.67 \pm 1.06$ & $1.74 \pm 0.80$ \\
\hline$p$-value & 0.086 & 0.311 & 0.299 \\
\hline \multicolumn{4}{|c|}{ Choice of specialty changed during studies } \\
\hline No & $3.10 \pm 0.92$ & $2.49 \pm 0.96$ & $1.68 \pm 0.81$ \\
\hline Yes & $3.02 \pm 0.97$ & $2.61 \pm 1.06$ & $1.63 \pm 0.79$ \\
\hline$p$-value & 0.605 & 0.433 & 0.682 \\
\hline \multicolumn{4}{|l|}{ University } \\
\hline US」 & $2.49 \pm 0.39$ & $2.02 \pm 0.57$ & $1.26 \pm 0.48$ \\
\hline USEK & $4.26 \pm 0.59$ & $3.72 \pm 0.79$ & $2.48 \pm 0.68$ \\
\hline$p$-value & $<0.001$ & $<0.001$ & $<0.001$ \\
\hline
\end{tabular}

Post-hoc analysis for the year of study: Autonomous motivation score (2nd vs 5th year $p=0.049$; 4th vs 5 th year $p=0.049$ ); Controlled motivation: 1 st vs 4 th year $p=0.03$; amotivation 1 st vs 4 th year $p=0.001$

vocation $(3.12 \pm 0.92, p=0.017)$, who did not choose to be a doctor for the liberal side of the job $(3.26 \pm 0.99$, $p<0.001)$, and who are still satisfied with their choice of going to medical school $(3.13 \pm 0.92, p=0.004)$.

Additionally, a higher mean controlled motivation score was found in students who lived with their parents $(2.59 \pm 1.04, p=0.016)$, and in those who chose to be a doctor because they considered it a business that earns money $(2.93 \pm 1.06, p=0.003)$.

Finally, a higher amotivation score was found in medical students who did not have a doctor in their family $(1.70 \pm 0.83, p=0.036)$, and in those who were not satisfied anymore with their choice of going to medical school (2.08 $\pm 0.99, p=0.002)$.

We also studied the correlation between the students' trainings and their motivation type (Table 4). We noticed that at USJ, students who were satisfied with their second-year training scored significantly higher on autonomous motivation $(2.54 \pm 0.32, p=0.027)$ than students who were not.

\section{Discussion}

Medical students' life can be very challenging across the years, and "motivation" may go through ups and downs. Motivation types may play a significant role throughout these tough years, modulating students' ambition and decisions [16-18]. We therefore conducted this study to identify the motivation types of Lebanese medical students gathered from two faculties. At the level of the whole sample, we were expecting autonomous motivation to increase over the years, as internship gets closer. Surprisingly, our main finding was that autonomous motivation actually remained predominant in all academic years. However, its highest level was observed in the second year, and its lowest level in the fifth year. The highest scores of controlled motivation and amotivation were observed in fourth-year students, and their lowest scores in first-year students. A study conducted in Brazil also showed a higher level of autonomous motivation in initial semesters of medical school (pre-clinical phase). However, it also showed higher levels of amotivation and extrinsic motivation with external regulation at later stages of medical school (clinical phase) [19]. This difference in motivation was attributed to the impact of learning environment, curriculum and medical school strategies: students have inherent characteristics when they enter medical school, but can become less intrinsically stimulated if courses are too theoretical and lack clinical contextualization [20]. Additionally, a study published in 2013 [11] described a decline in "idealism" (empathy and idealistic motivations) in fourth- and fifthyear medical students ("first-year medical student MS1" and "second-year medical student MS2"); it showed a shift of motives towards lifestyle, money, career and prestige [11]. Although "idealism" and "motivation" are two different concepts, the shift of motives described in the study refers to variables that are correlated with lower levels of self-determination ("lifestyle", "money", and "prestige"). Burnout could play a substantial role in the fourth and fifth year [21]. However, our students were enrolled from different academic years, and were not followed over a period of time to be able to establish a trend in motivation types. Therefore, it could be stipulated that some fourth- and fifth-year students had lower 
Table 4 Trainings satisfaction and motivation scores between both universities

\begin{tabular}{|c|c|c|c|}
\hline & Autonomous Motivation & Controlled motivation & Amotivation \\
\hline \multicolumn{4}{|l|}{ USJ } \\
\hline \multicolumn{4}{|c|}{ 2nd year training } \\
\hline No & $2.32 \pm 0.46$ & $2.08 \pm 0.54$ & $1.33 \pm 0.46$ \\
\hline Yes & $2.54 \pm 0.32$ & $2.01 \pm 0.63$ & $1.26 \pm 0.52$ \\
\hline$p$-value & 0.027 & 0.638 & 0.538 \\
\hline \multicolumn{4}{|c|}{ 3rd year training } \\
\hline No & $2.41 \pm 0.38$ & $2.11 \pm 0.58$ & $1.25 \pm 0.42$ \\
\hline Yes & $2.43 \pm 0.42$ & $2.05 \pm 0.56$ & $1.35 \pm 0.51$ \\
\hline$p$-value & 0.827 & 0.661 & 0.439 \\
\hline \multicolumn{4}{|c|}{ 4th year training } \\
\hline No & $2.24 \pm 0.47$ & $2.11 \pm 0.58$ & $1.46 \pm 0.57$ \\
\hline Yes & $2.45 \pm 0.36$ & $2.14 \pm 0.56$ & $1.23 \pm 0.37$ \\
\hline$p$-value & 0.135 & 0.878 & 0.147 \\
\hline \multicolumn{4}{|c|}{ 5th year training } \\
\hline No & $2.23 \pm 0.41$ & $2.21 \pm 0.50$ & $1.39 \pm 0.55$ \\
\hline Yes & $2.46 \pm 0.39$ & $2.09 \pm 0.58$ & $1.26 \pm 0.40$ \\
\hline$p$-value & 0.108 & 0.529 & 0.387 \\
\hline \multicolumn{4}{|l|}{ USEK } \\
\hline \multicolumn{4}{|c|}{$3 r d$ year training } \\
\hline No & $4.19 \pm 1.34$ & $3.76 \pm 1.28$ & $3.50 \pm 1.30$ \\
\hline Yes & $4.20 \pm 0.26$ & $3.41 \pm 0.58$ & $2.57 \pm 0.61$ \\
\hline$p$-value & 0.988 & 0.689 & 0.088 \\
\hline \multicolumn{4}{|c|}{ 4th year training } \\
\hline No & $3.73 \pm 1.03$ & $3.38 \pm 1.14$ & $3.41 \pm 1.23$ \\
\hline Yes & $4.26 \pm 0.23$ & $3.54 \pm 0.56$ & $2.44 \pm 0.43$ \\
\hline$p$-value & 0.465 & 0.747 & 0.304 \\
\hline \multicolumn{4}{|c|}{ 5th year training } \\
\hline No & $3.95 \pm 0.67$ & $3.45 \pm 0.76$ & $2.83 \pm 1.04$ \\
\hline Yes & $4.08 \pm 0.26$ & $3.08 \pm 0.41$ & $2.95 \pm 0.69$ \\
\hline$p$-value & 0.701 & 0.360 & 0.836 \\
\hline
\end{tabular}

levels of self-determination since the beginning of their studies.

Moreover, our study showed that students who were still satisfied with their choice of going to medical school had high autonomous motivation. Sobral et al. established a similar positive correlation between autonomous motivation and students' intention to continue studies [12].

We expected to find higher levels of self-determination in women, as previously published by Sobral et al. [12] and Kusurkar et al. [13]. However, the difference between genders was not statistically significant in our study. This may be due to the small sample size and the lower response rate compared to the previously mentioned studies.

Higher levels of autonomous motivation were observed in students from USJ who enjoyed their second year training, compared to those who did not. In a study conducted by Ayoub et al. at USJ [14], a positive experience in trainings was shown to increase self-determination in interns. Early contacts with patients through trainings are increasingly studied, and had been shown to be associated with higher levels of autonomous motivation [22-25].

Many studies showed that when autonomous motivation increases, professional outcome and wellbeing of students increase as well [26]. For instance, Kusurkar et al. [4, 27] demonstrated that when the level of self-determination is high, study efforts, deep learning, and academic performance are greater, with a low level of exhaustion. Isik et al. showed that autonomous motivation correlates with higher GPAs [28]. In contrast, another study showed that amotivation is linked to depression and significantly affects medical education outcomes [29]. In both faculties, many measures have already been implemented in order to 
increase intrinsic motivation. For instance, frequent trainings at the hospital exist, ensuring an early contact with patients and breaking the routine of classes. Additionally, active learning methods are frequently used at the Faculty of Medicine at USJ, such as problem-based learning and small study groups. Soon, a simulation center will also be opened on campus. As for USEK, early contact with patients is ensured through consistent trainings on the field in early years. Although autonomous motivation is the predominating type overall, continuous development of the learning environment may further decrease controlled motivation and amotivation scores, particularly in the fourth and fifth year.

\section{Implications of our findings}

Both faculties have already integrated measures that enhance autonomous motivation in their curricula, such as early contact with patients and problem-based learning. Our results suggest that those measures were successful. However, both faculties could benefit from re-enforcing and enhancing those measures, particularly in the fourth and fifth year, in order to maintain a high level of autonomous motivation among students throughout their program. New measures could also be proposed to stimulate autonomous motivation in students $[6,30]$. First of all, students' activities should be valued since the first year; this may be accomplished by linking theory to practice as much as possible, and would be particularly beneficial in fields of basic sciences, such as biochemistry [10]. Moreover, the perception of autonomy and control should be increased in students, by giving choices throughout the learning process as much as possible $[4,17,26,31]$. For instance, students should have the possibility to choose their courses, schedules, and training sites. Encouraging participation and strengthening self-efficacy affects performance positively [32]. The perception of competence should also be enhanced, by giving positive and constructive feedbacks [33]. The need for relatedness should be fulfilled as well, through open-mindedness of teachers and other students, discussion, and interest for others. Finally, teachers should choose learning methods that are intrinsically motivating [34, 35], such as problem-based learning, or simulation of clinical situations. They should also use external factors that do not alter intrinsic motivation. This last suggestion is the most difficult to apply, due to the importance of ranking and grading systems, which cannot be easily suppressed. However, the content of examinations could be modified: the whole course should be evaluated, not just restrictive aspects and details that require merely memorization. Finally, early contacts with patients should be maintained and multiplied in both faculties. A positively-perceived learning environment enhances students' satisfaction, autonomous motivation and behaviors, and leads to greater academic outcomes [33, 36, 37].

\section{Limitations and strengths}

The main limitation of the study was the insufficient number of answers in both faculties, but this is also a valuable information: it may be that the students who did not answer the survey were less intrinsically motivated. A selection bias is present since this study approached two out of seven medical faculties in Lebanon, thus, results cannot be extrapolated to all Lebanese medical students. Information bias might be present since some students might over- or underestimate certain questions/answers. To the best of our knowledge, this study is the first in Lebanon to tackle this topic. It is a first step towards raising awareness among both teachers and students at the faculties of medicine to increase autonomous motivation; this would improve professional outcome, wellbeing, self-satisfaction and performance of medical students.

\section{Conclusions}

This study showed high levels of autonomous motivation in the first five years of medical school. Autonomous motivation was the predominant type in the whole sample. The highest scores of controlled motivation and amotivation were noted in the fourth year. Moreover, high levels of self-determination were seen in students who enjoyed their early contacts with patients through trainings. Actions should be implemented in medical schools to enhance and maintain autonomous motivation, and consequently students' outcome and health-care quality.

\section{Abbreviations}

AMOT: Amotivation; ERM: External Extrinsic Motivation; MEID: Extrinsic Motivation by Identified Regulation; MEIN: Extrinsic motivation by introjected regulation; MIAC: Intrinsic Motivation for Accomplishment; MICO: Intrinsic Motivation to Knowledge; MIST: Motivation intrinsic to stimulation; SPSS: Statistical Package for Social Sciences; USEK: Holy Spirit University of Kaslik; USJ: Saint-Joseph University of Beirut

\section{Acknowledgements}

We would like to thank Pr. Roland Tomb and Pr. Jean-Claude Lahoud, Deans of the Faculties of Medicine at the Saint-Joseph University and Holy Spirit University of Kaslik, respectively, for giving us the permission to conduct this study in their respective faculties. We would like to thank as well all students who agreed to participate in these studies.

\section{Authors' contribution}

ASS and ENA conceived and designed the surveys. ASS performed the data collection. ASS, SH, AH and ENA involved to data interpretation and statistical analysis. ASS wrote the manuscript. AK, DKS and AS critically revised the manuscript for intellectual content. All authors read and approved the final manuscript.

\section{Funding}

None.

\section{Availability of data and materials}

All data generated or analyzed during this study are not publicly available to maintain the privacy of the individuals' identities. The dataset supporting the conclusions is available upon request to the corresponding author.

Ethics approval and consent to participate

The Hotel-Dieu de France Ethical committee approved this study based on the fact that it was an observational study that respected participants' 
autonomy and confidentiality (Reference number: CEHDFTfem/2016/63). A written consent was obtained from all students.

\section{Consent for publication}

Not applicable.

\section{Competing interests}

The authors have nothing to disclose.

\begin{abstract}
Author details
${ }^{1}$ Faculty of Medicine, Saint-Joseph University, Beirut, Lebanon. ${ }^{2}$ Faculty of Medicine and Medical Sciences, Holy Spirit University of Kaslik (USEK), Jounieh, Lebanon. ${ }^{3}$ INSPECT-LB : Institut National de Santé Publique, Epidémiologie Clinique et Toxicologie, Beirut, Lebanon. ${ }^{4}$ Faculty of Pharmacy, Saint-Joseph University, Beirut, Lebanon. ${ }^{5}$ Laboratory of Pharmacology, Clinical Pharmacy and Quality Control of Drugs, Faculty of Pharmacy, Pôle Technologie-Santé (PTS), Faculty of Pharmacy, Saint-Joseph University, Beirut 1107 2180, Lebanon. 'Laboratory of Molecular Microbiology, Faculty of Pharmacy, Saint-Joseph University, Pôle Technologie-Santé (PTS), Faculty of Pharmacy, Saint-Joseph University, Beirut 1107 2180, Lebanon. 'Department of Cardiology, Hôtel-Dieu de France Hospital, Beirut, Lebanon. ${ }^{8}$ Department of Anesthesiology and reanimation, Hôtel-Dieu de France Hospital, Beirut, Lebanon.
\end{abstract}

Received: 30 August 2019 Accepted: 19 March 2020

Published online: 31 March 2020

\section{References}

1. Oxford dictionnary, https://en.oxforddictionaries.com/definition/motivation Accessed 27 July 2018.

2. Gagne M, Deci EL. Self-determination theory and work motivation. J Organiz Behav. 2005;26:331-62.

3. Gagné M, Deci EL. Self-determination theory and work motivation. J Organ Behav. 2005;26(4):331-62.

4. Kusurkar RA, Croiset G, Galindo-Garre F, Ten Cate O. Motivational profiles of medical students: association with study effort, academic performance and exhaustion. BMC Med Educ. 2013:13:87.

5. Orsini $C$, Evans $P$, Jerez $O$. How to encourage intrinsic motivation in the clinical teaching environment?: a systematic review from the selfdetermination theory. J Educ Eval Health Prof. 2015;12:8.

6. Kusurkar RA, Croiset G, Ten Cate TJ. Twelve tips to stimulate intrinsic motivation in students through autonomy-supportive classroom teaching derived from self-determination theory. Med Teach. 2011;33(12):978-82.

7. Niemiec CP, Ryan RM. Autonomy, competence, and relatedness in the classroom: applying self-determination theory to educational practice. Theory Res Educ. 2009;7(2):133-44.

8. Ryan RM, Deci EL. Self-determination theory and the facilitation of intrinsic motivation, social development, and well-being. Am Psychol. 2000;55(1):68.

9. Ryan RM, Deci EL. Intrinsic and extrinsic motivations: classic definitions and new directions. Contemp Educ Psychol. 2000;25(1):54-67.

10. Pelaccia T, Delplancq H, Triby E, Leman C, Bartier J-C, Dupeyron J-P. La motivation en formation: une dimension réhabilitée dans un environnement d'apprentissage en mutation. Pédagog Méd. 2008;9(2):103-21.

11. Morley CP, Roseamelia C, Smith JA, Villarreal AL. Decline of medical student idealism in the first and second year of medical school: a survey of preclinical medical students at one institution. Med Educ Online. 2013;18:21194

12. Sobral DT. What kind of motivation drives medical students' learning quests? Med Educ. 2004;38(9):950-7.

13. Kusurkar R, Kruitwagen C, ten Cate O, Croiset G. Effects of age, gender and educational background on strength of motivation for medical school. Adv Health Sci Educ Theory Pract. 2010;15(3):303-13.

14. Ayoub E: [Motivation des étudiants de sixième et septième année aux stages cliniques]. 2016.

15. Thill E, Vallerand RJ: Introduction à la psychologie de la motivation: [Laval, Québec]: Éditions Études vivantes; 1993.

16. Kusurkar RA, Ten Cate TJ, van Asperen M, Croiset G. Motivation as an independent and a dependent variable in medical education: a review of the literature. Med Teach. 2011;33(5):e242-62.

17. Niemiec CP, Ryan RM. Autonomy, competence, and relatedness in the classroom: applying self-determination theory to educational practice. School Field. 2009;7(2):133-44.
18. Kusurkar RA, Croiset G, Mann KV, Custers E, Ten Cate O. Have motivation theories guided the development and reform of medical education curricula? A review of the literature. Acad Med. 2012;87(6):735-43.

19. GMCd S, Borges AR, OdS E, ALG L, Lucchetti G. Comparison of students' motivation at different phases of medical school. Rev Assoc Méd Bras. 2018;64(10):902-8.

20. Del-Ben CM, Machado VF, Madisson MM, Resende TL, Valerio FP, Troncon LE. Relationship between academic performance and affective changes during the first year at medical school. Med Teach. 2013;35(5):404-10.

21. Enoch L, Chibnall JT, Schindler DL, Slavin SJ. Association of medical student burnout with residency specialty choice. Med Educ. 2013;47(2):173-81.

22. von Below B, Hellquist G, Rodjer S, Gunnarsson R, Bjorkelund C, Wahlqvist M. Medical students' and facilitators' experiences of an early professional contact course: active and motivated students, strained facilitators. BMC Med Educ. 2008:8:56.

23. Graungaard AH, Andersen JS. Meeting real patients: a qualitative study of medical students' experiences of early patient contact. Educ Prim Care. 2014;25(3):132-9.

24. Diemers AD, van de Wiel MW, Scherpbier AJ, Baarveld F, Dolmans DH. Diagnostic reasoning and underlying knowledge of students with preclinical patient contacts in PBL. Med Educ. 2015;49(12):1229-38.

25. Diemers AD, Dolmans DH, Verwijnen MG, Heineman E, Scherpbier AJ. Students' opinions about the effects of preclinical patient contacts on their learning. Adv Health Sci Educ Theory Pract. 2008;13(5):633-47.

26. Black $A E$, Deci EL. The effects of instructors' autonomy support and students' autonomous motivation on learning organic chemistry: a selfdetermination theory perspective. Sci Educ. 2000;84(6):740-56.

27. Kusurkar RA, Ten Cate TJ, Vos CM, Westers P, Croiset G. How motivation affects academic performance: a structural equation modelling analysis. Adv Health Sci Educ Theory Pract. 2013;18(1):57-69.

28. Isik U, Wouters A, Ter Wee MM, Croiset G, Kusurkar RA. Motivation and academic performance of medical students from ethnic minorities and majority: a comparative study. BMC Med Educ. 2017;17(1):233.

29. Kunanitthaworn N, Wongpakaran T, Wongpakaran N, Paiboonsithiwong S, Songtrijuck N, Kuntawong P. Factors associated with motivation in medical education: a path analysis. BMC Med Educ. 2018;18(1):140.

30. Kusurkar RA, Croiset G. Autonomy support for autonomous motivation in medical education. Med Educ Online. 2015;20:27951.

31. Bentata Y, Delfosse C. Peut-on améliorer la motivation des étudiants en médecine pour un cours fondamental de physiologie en intégrant à l'exposé magistral quelques méthodes pédagogiques actives? Pan Afr Med J. 2017;28:315.

32. Stegers-Jager KM, Cohen-Schotanus J, Themmen AP. Motivation, learning strategies, participation and medical school performance. Med Educ. 2012;46(7):678-88.

33. O'Sullivan PS. What's in a learning environment? Recognizing teachers' roles in shaping a learning environment to support competency. Perspect Med Educ. 2015;4(6):277-9.

34. Hariri-Akbari M, Shokrvash B, Mahmoodi F, Jahanjoo-Aminabad F, Yousefi B, Azabdaftari F. Conversion of extrinsic into intrinsic motivation and computer based testing (CBT). BMC Med Educ. 2018;18(1):143.

35. Ten Cate O. Medical education in the Netherlands. Med Teach. 2007;29(8):752-7.

36. Schonrock-Adema J, Bouwkamp-Timmer T, van Hell EA, Cohen-Schotanus J. Key elements in assessing the educational environment: where is the theory? Adv Health Sci Educ Theory Pract. 2012;17(5):727-42.

37. Sobral DT. Medical students' self-appraisal of first-year learning outcomes: use of the course valuing inventory. Med Teach. 2004;26(3):234-8.

\section{Publisher's Note}

Springer Nature remains neutral with regard to jurisdictional claims in published maps and institutional affiliations.

Ready to submit your research? Choose BMC and benefit from:

- fast, convenient online submission

- thorough peer review by experienced researchers in your field

- rapid publication on acceptance

- support for research data, including large and complex data types

- gold Open Access which fosters wider collaboration and increased citations

- maximum visibility for your research: over $100 \mathrm{M}$ website views per year

At $\mathrm{BMC}$, research is always in progress.

Learn more biomedcentral.com/submissions 